\title{
Intrauterine diagnosis of proximal jejunal atresia in a neonate conceived by assisted conception technique: a case report
}

\author{
Adebiyi Gbadebo Adesiyun ${ }^{1 *}$, Modupeola Omotara Samaila ${ }^{2}$, Ayodele Cole Benson ${ }^{3}$ \\ ${ }^{1}$ Department of Obstetrics \& Gynaecology, Ahmadu Bello University Teaching Hospital, Zaria, Nigeria; \\ ${ }^{2}$ Department of Pathology, Ahmadu Bello University Teaching Hospital, Zaria, Nigeria; \\ ${ }^{3}$ Echo-Scan Services Limited, Kaduna, Nigeria. \\ E-mail: Biyi.adesiyun@yahoo.com
}

Received 4 July 2011; revised 4 August 2011; accepted 11 August 2011.

\begin{abstract}
Jejunal atresia is an entity within an array of congenital intestinal anomalies. We present a case of antepartum diagnosis of proximal jejunal atresia in a baby conceived through assisted conception.
\end{abstract}

Keywords: Antepartum Diagnosis; Jejunal Atresia; Ultrasound Scan; Assisted Conception

\section{INTRODUCTION}

Jejunal atresia is a congenital intestinal anomaly seen in neonates [1]. The common clinical presentation is intestinal obstruction, usually within few days of birth [2]. There are conflicting reports on the association of assisted conception and birth defects, however some authors [3] have reported positive correlation with some birth defects like neural tube defects, atresias and heart defects Although, other authors have argued that maternal characteristic like age, factors responsible for infertility and concurrent diseases may have influenced the increase in birth defects and not the treatment itself [3]. This is a case report of fetal jejunal atresia diagnosed by antepartum sonographic evaluation at a gestational age of twenty six weeks. Fetal jejunal atresia, though a rare entity, its diagnosis in utero is yet to be reported from any resource constrained setting like ours.

\section{CASE REPORT}

A thirty one year old primigravid woman presented with six months history of amenorrhea and two weeks history of abdominal discomfort. There was no associated history of bleeding per vaginum, drainage of liquor or urinary symptoms. She conceived through invitrofertilization and intracytoplasmic sperm injection as a result of severe oligoasthenospermia. Physical examination showed a healthy looking woman that was not pale or jaundiced. Her temperature was $37^{\circ}$, pulse rate was $76 / \mathrm{min}$ and her blood pressure was 100/70 mmHg. Abdominal examination showed a fundal height consistent with thirty two weeks gestation. The fetal lie and presentation could not be defined. A diagnosis of large for gestational age uterus was made, to rule out multiple gestation and hydramnios. Investigations done included a full blood count, urea and electrolyte, urinalysis and sugar profile; these were normal. An obstetric ultrasound showed a live singleton fetus at a gestational age of twenty five weeks and four days, moderate polyhydramnious and "triple bubble" sign in the fetal abdomen (Figure 1). An ultrasonic diagnosis of fetal jejunal atresia was made.

Patient was subsequently booked for antenatal care; she was placed on haematinics (daily oral ferrous sulphate, folic acid) and prophylactic antimalaria (three tablets of sulfadoxine/pyrimethamine combination). Both patient and spouse were informed and counseled on the possible implication of the sonographic finding. She thereafter defaulted from antenatal clinic attendance at thirty two weeks gestation.

Patient later presented with history of spontaneous va-

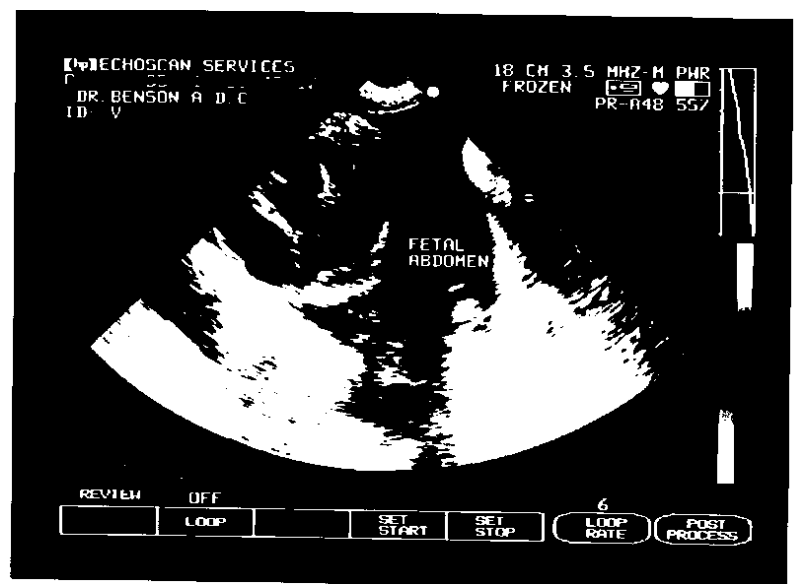

Figure 1. SONOGRAPHIC TRIPLE BUBBLE, sign in the fetal abdomen. 
ginal delivery at a private hospital, three days before presentation. She had an uneventful delivery of a term male neonate, who had been vomiting, with associated abdominal distention and difficulty in breathing. The baby was yet to pass meconium. Examination of the baby revealed a body weight of $2.4 \mathrm{~kg}$, with moderate pallor, dehydration and pyrexia of $38^{\circ}$. The respiratory rate was $140 /$ min with crepitations over the lung field. There was moderate abdominal distension. A diagnosis of neonatal intestinal obstruction and aspiration pneumonitis was made. The baby was optimized for surgery .The intra operative findings were consistent with intestinal obstruction secondary to proximal jejunal atresia. This was confirmed by histopathologic assessment of the specimen that showed distortion of the architecture of the wall by fibromuscular tissue extending into the submucosa and mucosa, and creating a trapped mucosa, papillae and bridging fibrosis (Figure 2).

\section{DISCUSSION}

In this report, intrauterine diagnosis of fetal jejunal atresia was based on ultrasonographic "triple bubble" sign in the fetal abdomen [4,5]. This sign is fairly speci- fic for jejunal atresia [5]. Aetiologically, jejunal atresia develops as a result of intrauterine ischaemic event or vascular accident leading to absorption of necrotic sterile bowel [6]. Parvovirus B19 infection has also been impli- cated in its causation [7]. The prevalence of jejunal atresia is about 1 per 3000 live births [8]. Though the patient was a male child, there is no sex predilection in the pathogenesis of this anomaly [9]. Its occurrence is higher in monozygotic twins compared to singleton and dizygotic twins [10]. Jejunal atresia can occur as part of complex congenital anomalies in $10 \%$ to $30 \%$ of cases [6]. Cystic fibrosis, renal dysplasia and atresia of the biliary tract could be associated with it.

The classic presentation of bilous vomiting and abdominal distension was observed in this neonate. Maternal polyhydramious which was present in this case, is said to occur in about $9 \%$ of cases with intestinal atresia and stenosis [2]. Passage of meconium before presentation is not an uncommon finding [2], though the baby being reported had not passed meconium at presentation to the emergency. The importance of "triple bubble: sign on erect abdominal radiograph of neonates with jejunal atresia should not be neglected, especially in a resource constrained settings like ours [11].

The treatment of proximal jejuna atresia is mainly surgical. However, the availability of parenteral nutrition, neonatal intensive care unit and improved pediatric anesthesia could improve the survival of these patients [12]. In this case report, should the ultrasonographic "triple bubble” sign which is fairly specific for jejunal atresia,

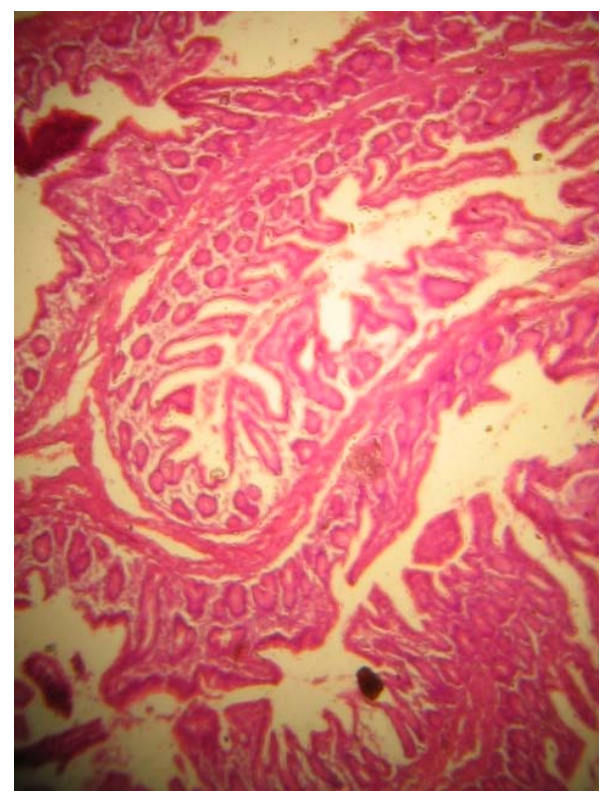

Figure 2. Microscopic appearance of proximal jejuna atresia.

was accorded due recognition and attention by the physicians and patients, it would have aided in close observation and early intervention after birth, thus preventing vascular complications like gangrene and perforation which the baby was fortunate not to have. Furthermore, lack of weighted emphasis on the sonographic finding during counseling may have been the reason why the patient defected to a private health facility to deliver and not to have informed the health personnel's of the earlier ultrasound finding.

The overall survival of about $90 \%$ was recorded in developed countries following management of proximal jejuna atresia [12] as against $50 \%$ to $60 \%$ reported from developing countries $[2,13]$. However, against all odds this baby survived.

\section{REFERENCES}

[1] Chang, W.C., Chen, H.C. and Peng, H.C. (1995) Jejunoileal atresia in neonates. Chang Hua/Hsueh Tsa Chih Taipei, 56, 36-39.

[2] Ameh, E.A. and Nmadu, P.T. (2000) Intestinal atresia and stenosis: A retrospective analysis of presentation, morbidity and mortality in Zaria, Nigeria. West African Journal of Medicine, 19, 39-42.

[3] Balen, A.H. (2008) Assisted conception, ethics and the human fertilisation and embryology authority. In: Infertility in practice, balen. Informa Healthcare, London. 3rd Edition, 289-353.

[4] Benson, A.C. (2005) Congenital obstetric anomalies. In: Basic atlas of diagnostic ultrasound. Cole BA. Spectrum Books Limited, Ibadan, 98.

[5] Ola-Ojo, O.O. (2005) Obstetrics-2nd and 3rd trimester. Obstetric and gynecology ultrasound, a self assessment 
guide. Elsevier, Churchill Livingstone, London, 326.

[6] Haler, J.A., Tepas, J.J., Pickard, L.R. and Shermeta, D.W. (1983) Intestinal atresia: Correct concept of pathogenesis, pathophysiology and operative management. The American Journal of Surgery, 49, 385-391.

[7] Schild, R.L. and Hansmann, M. (1988) Small bowel atresia: Antenatal intestinal vascular accident or parvovirus BIG infection? Obstetric and gynecology ultrasound, 11, 227. doi:10.1046/j.1469-0705.1998.11030225-2.x

[8] Danhert, W. (1996) Gastrointestinal tract. In: Mitchell EW, ed. Radiology review manual. 3rd Edition. Williams \& Wilkins, Baltimore, 541-632.

[9] Kirks, D.R. and Caron, K.H. (1991) Gastrointestinal tract. In: Kirks DR, ed. Practical pediatric imaging: Diagnostic radiology on infants and children, 2nd Edition. Little,
Brown, Boston, 709-904.

[10] Wyllie, R. (1996) Intestinal atresia, stenosis and malrotation. In: Berhaman RE, Kliegman RM, Arvin AM eds. Nelson textbook of padiatrics, 15th Edition, Philadelphia: WB Saunders Company, 1063-1067.

[11] Amole, A.O., Johnson, R.A.W.B. and Adesiyun, O.A.M. (2003) Triple bubble sign. A neglected radiological feature of proximal jejunal atresia. The International Journal of Radiology, 3.

[12] Dillon, P.W.A. and Cilley, R.E. (1993) Newbornsurgical emergencies, gastrointestinal anomalies and abdominal wall defects. Pediatr Clinics of North America, 409, 12891314.

[13] Adejuyigbe, O., Jeje, E.A., Owa, J. and Adeoba, E.A. (1992) Neonatal intestinal obstruction in Ile Ife, Nigeria. Nigeral Medicine Journal, 22, 24-28. 